\title{
Role of Life Style Factors with Respect to Semen Quality and ART
}

\begin{abstract}
One of the most painful problems of marital life is infertility. There are various causes of infertility such as endometriosis, ovulatory disorder, chromosomal abnormalities, semen quality and idiopathic infertility. The current approaches in the treatment of infertility, the problem could be resolved to some extent by adopting modern treatment and procedures as well as healthy lifestyle. In last few years remarkable changes have been observed in our environment, diet and lifestyle. The effect of lifestyle factors on human reproductive potential might be varying because of circumstances or individual susceptibility. The incidence of male infertility is one of the rise probably due to environmental factors, psychosomatic disorders, stress as well as personal habits including medications. Special attention has been devoted in the scientific literature that is well established as health risks, viz. smoking, alcohol and obesity. Other factors that are being considered in the literature are abuse of drugs, genital health heat stress, physiological stress and effects of cellular phones. Assisted reproductive technology provides a means to bypass their woes. Several techniques exist depending on the extent of the infertility.

Keywords-ART, BMI, PAHs, IUI, IVF, ICSI, IMSI, MSOME.
\end{abstract}

\section{Introduction}

In recent years, infertility has become the subject of significant media attention and public discussions, particularly in light of new advances in the technology of assisted reproduction. It has been proposed that a man who fails at fertility is likely to evaluate himself as sexually inadequate and may experience temporary impotence and decreased sexual desire. In India, approximately 15 percent of couples are unable to initiate a pregnancy without some form of assistance or therapy. These patients are said to be "primary infertile". In approximate 2 percent of these couples there are factors other than seminal abnormalities which prevent conception. It is imperative that these groups of patients are properly diagnosed and treated to enable them to achieve conception. Male infertility contributes to about 50 percent of total infertility problem according to large world health organization [WHO] study of more than 8,500 couples $^{[66]}$. As is expected there is a wide variety of causes associated with it. It seems logical and cost effective to address male factors first, and managed together with the evaluation and management of the female partner.

\section{Life Style Factors \\ Smoking}

Cigarette smoking is known for formation of cancer [14]. There is also considerable evidence that smoking adversely affect male reproductive health. 
Some studies have found the effect of same on sperm volume ${ }^{[1]}$. It is indicative that smoking has harmful effect on human male fertility ${ }^{[2]}$. Tobacco effects can be observed at both, microscopic and molecular levels. Microscopically there is an effect on sperm concentration, motility and morphology ${ }^{\text {[3- }}$ ${ }^{10]}$. At the molecular level there is increased risk of sperm aneuploidy ${ }^{[11,12]}$. Furthermore, maternal smoking during pregnancy may have an adverse and irreversible effect on semen quality in male descendants ${ }^{[13]}$, besides a high risk of birth defects and childhood cancers in the offspring ${ }^{[14]}$.

\section{Alcohol}

Alcoholism has been long associated with reproductive health disturbances ${ }^{[15]}$ sperm quality is seems to be deteriorate progressively with increasing level of alcohol intake ${ }^{[16]}$. chronic alcohol consumption has a detrimental effect on male reproductive hormones and one semen quality [18]. A case control study is conducted in Japan showed that alcohol intake was significantly more common in infertile men than in non drinkers ${ }^{[19]}$. An alcohol exposure in "in-vitro"induces reduction of sperm motility and morphology and the response is dose-related ${ }^{[20]}$.

\section{Obesity}

A common observation in the western world is the increased average body mass index (BMI) in the general population that has resulted in an increased prevalence of obesity. Several studies have associated with lower semen parameters due to obesity ${ }^{[21,22]}$. In a follow up study in couples enrolled in the agricultural health study in USA ${ }^{[23]}$ found a dose-response relationship between infertility and male BMI and that association was similar for older or younger men. Other authors have found that semen parameters are affected in men BMI above or below normal levels [24-29]. Maternal BMI may also have effect on the semen quality in sons of overweight mothers.

\section{Recreational Drug Use \& Genital Heat Stress}

Cocaine use for five or more years was more common in men with sperm motility, low concentration or large proportion of abnormal forms ${ }^{[30]}$. Normal sperm production depends on an optical testicular temperature maintained below body temperature which is typically around 34-350 C ${ }^{[31]}$. Several experimental studies have shown that heat exposures may reduce semen quality [32-34]. In observational studies it has been found that individuals involved in activates that increase scrotal temperature have poor sperm morphology [35]. It has also been studied that the type of underwear used lead to increase in the scrotal temperature $^{[36]}$ and results indicated that scrotal temperature in volunteers wearing wool trouser and shirt fitting to body size were significantly higher for tight versus loose fitting.

\section{Psychological Stress}

The impact of psychological stress on semen quality is an area of great interest in which the further research is needed. Motility and morphologically normal spermatozoa decrease in healthy subjects undergoing examination stress ${ }^{[37]}$. In male involved in IVF procedures, the quality of the semen sample obtained on the same day, when eggs retrieval was performed was significantly worse than the first sample analyzed in the same patients collected before undergoing IVF procedures. The decline in the semen quality in the second sample was attributed to the psychological stress involved in that clinical process ${ }^{[38,39]}$.

\section{Cellular telephone Use}

There has been increasing concern about the possibility that the use of cell phones could affect our health and male reproductive system. As cell phones produce radio frequency electromagnetic waves, and few observational studies have shown that the prolonged usage of cell phones have negative effects of sperm parameters like sperm count, motility, viability and normal morphology ${ }^{[40-}$ 42].

\section{Occupational and Environmental factors}

Pesticides ${ }^{[43-44]}$, several heavy metals like lead or cadmium ${ }^{[45-47]}$ and several air pollutants (PAHs, dioxins) ${ }^{[48,49]}$ have been shown to compromise the reproductive male function. Several studies have explored and compared men's semen parameters and occupational exposures in male partners of infertile couples attending infertility clinics ${ }^{[46,50,54-}$ 
${ }^{56]}$. Association has been found between welder and reduced sperm count and motility ${ }^{[46,54]}$. In other case-controlled studies infertile men had been more frequently exposed to organic solvents [52,53,56], electromagnetic fields and heavy metals than fertile men ${ }^{[46,53,55]}$. Several solvents affect human semen quality ${ }^{[17,51]}$, proportionally to the amount and time of exposure ${ }^{[52,53]}$. Semen quality in workers exposed occupationally to hydrocarbons like toluene, benzene and xylene lead to existence of anomalies in viscosity, liquefaction capacity, sperm count, sperm motility and proportion of sperm with normal morphology compared with unexposed males ${ }^{[57,58]}$.

The below Table shows Studies investigated by WHO [14,15,23,31,37,40] worldwide on influence of above life style factors on semen quality.

Table 1. Influence of life style factors on semen quality

\begin{tabular}{|l|c|c|}
\hline S. No & Life style factor & $\begin{array}{c}\text { Total Infertile } \\
\text { Men Population }\end{array}$ \\
\hline 1 & Alcohol & $<42 \%$ \\
\hline 2 & Smoking & $<13 \%$ \\
\hline 3 & obesity & $<2.7 \%$ \\
\hline 4 & Recreational Drugs & $<1 \%$ \\
\hline 5 & Genital Heat Stress & \multirow{2}{*}{$<2 \%$} \\
\hline 6 & Psychological Stress & \\
\hline 7 & $\begin{array}{c}\text { Occupational and } \\
\text { Environmental factors }\end{array}$ & $<0.3 \%$ \\
\hline 8 & Cellular telephone Use & \\
\hline
\end{tabular}

\section{Assisted reproductive technology}

With the growing trend of male factor infertility ${ }^{[59]}$ and desire for infertile couples to reproduce, assisted reproductive technology provides a means to bypass their woes. Several techniques exist depending on the extent of the infertility.

\section{IUI (IntraUterine Insemination)}

Intrauterine insemination as an infertility therapy that has regained its use due to the improvement of the sperm preparation and washing procedures. This technique is used when there is semen with a low concentration of sperm, and involves artificial insemination after induced ovulation. IUI is cheaper, simpler, and less invasive than the more sophisticated assisted reproductive methods like
IVF and ICSI. IUI is therefore, often offered to couples as a first line approach in cases of, antisperm, antibodies or idiopathic infertility ${ }^{[60]}$.

\section{IVF (In Vitro Fertilization)}

The development of IVF procedures as a novel infertility therapy directly caused the establishment of a model where certain sperm variables such as morphology could be studied ${ }^{[61]}$. The model for the sperm morphology mainly based on the appearance of a normal sperm cell. This technique is used when complete lack of sperm count in ejaculation. IVF attempts to imitate fertilization outside of the human body, by placing sperm in the vicinity of the oocyte and allowing fertilization to proceed with the help of various reagents. Logistic regression analysis was used to determine the threshold for fertilization using sperm morphology as contributing factor ${ }^{[62 \text {, }}$ 63].

\section{ICSI (IntraCytoplasmic Sperm Injection)}

ICSI involves mechanical breeching of the oocyte and injection of single sperm in to the cytoplasm. When comparing ICSI with other ART procedures it has relatively lesser amount of limiting factors, because it requires the least amount of available sperm and can utilize immature and immotile sperm for the procedure. Recently a new method of Intracytoplasmic morphologically selected sperm injection has been proposed based on motile sperm organellar examination that results in a high pregnancy and decreased incidence of abortion.

\section{MSOME (Motile sperm organelle Morphology} examination)

Sperm functional morphology criteria based on real time observation of individual motile sperm cells under high magnification were developed. MSOME being able to detect subtle sperm morphological malformations, which might remain unnoticed during standard microinjection, and allow the identification of spermatozoa with the best morphology, was introduced to improve the ICSI success rates.

IMSI (Intracytoplasmic Morphologically Selected Sperm Injection)

MSOME evaluation coupled with conventional ICSI gave rise to new micromanipulation technique 
called intracytoplasmic morphologically selected sperm injection. Which is the currently one of the most debated issues in the ART field.

\section{Materials and methods}

The study was carried out among the 221 male (Age group of 20 - 45 years). Semen samples were obtained by masturbation within 3-6 days of sexual abstinence in a wide-mouth sterile container. Morphology of sperms were evaluated as per WHO criteria $^{[64]}$. Semen sample were observed using 40x magnifications under the light microscope (OLYMPUS BX41). Sperm morphology was checked in semen samples using papanicolaou staining method ${ }^{[65]}$. A total of two hundred sperms were counted and categorized as below:

i. Morphologically normal sperm: Sperm with an oval head followed by distinct midpiece region, normal tail and clear well defined acrosomal area ( $40-70 \%$ of the head area).

ii. Morphologically defective sperms: Head shape abnormality, midpiece defect, tail and multiple defects.

All the cells which did not present any overlap with debris or other cells were considered for analysis. Images were analyzed with ImageJ open source software ${ }^{[66]}$ using custom macros to implement the procedure described below.

1. If the image is in RGB form, it is transformed to a gray scale image.

2. Then filtered using unsharp mask filter to increase the intensity of the sperm cells

3. Thresholding is done on the image such that shape of the all sperm cells will be appeared.

4. Image is calibrated to measure the various parameters on sperm head.



Figure 1.Orignal Image

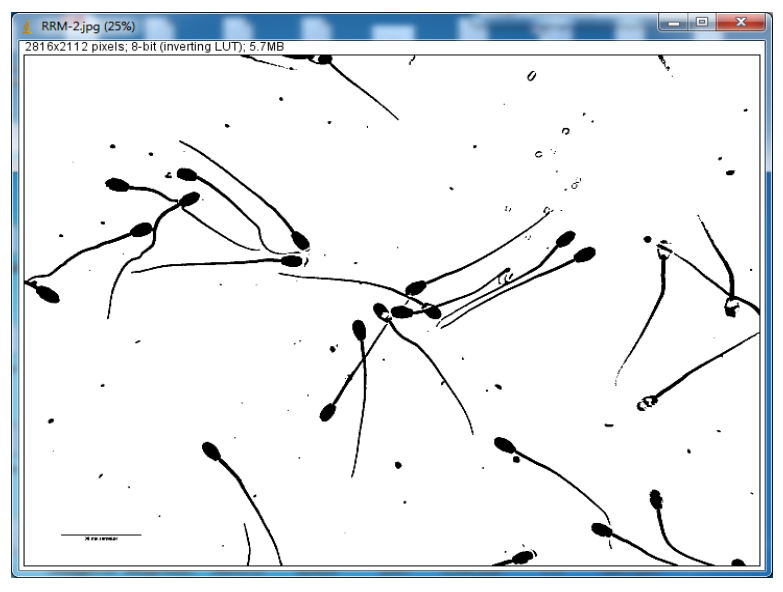

Figure 2.Thresholed Image

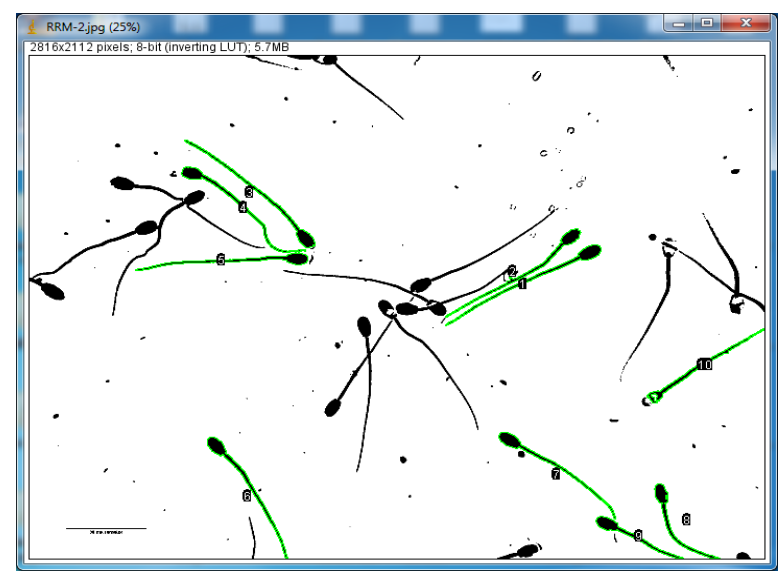

Figure 3.Sperm with mask and label

The above figures show analysis on sperm sample which is taken from system microscope first RGB image is converted to 8 bit gray scale. Then Thresholding is made on the image to differentiate sperm cells with respect to background. Next particle analysis is achieved to remove the noise and produce a mask on all sperm cells available in the image. Finally using ROI manager labelling and measurement is carried out on each sperm cell. Morphometric measurements carried out on human sperm

\section{Results}

The general characteristics of the study population such as area of residence, educational status and dietary habits have been shown in the following figure 4 to figure 7 


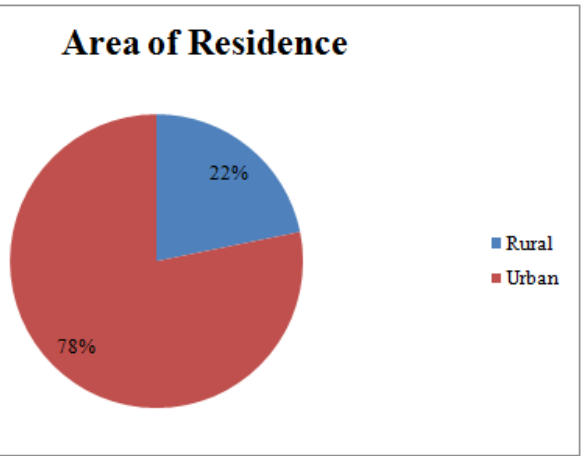

Figure 4.Study Population of Area of Residence

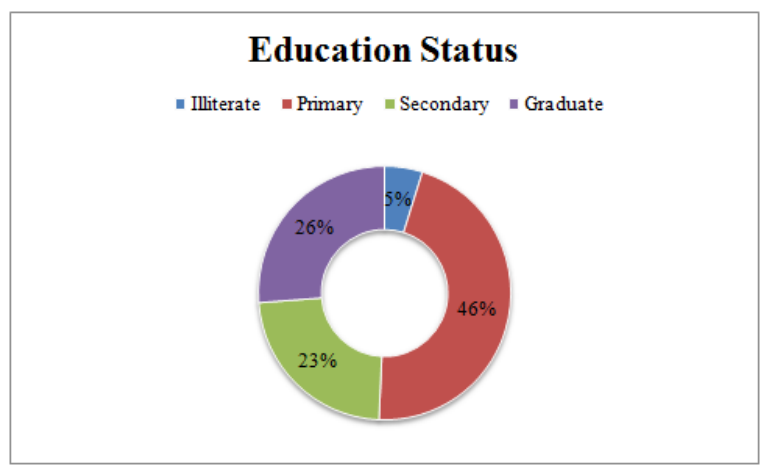

Figure 5.Study population of Education status

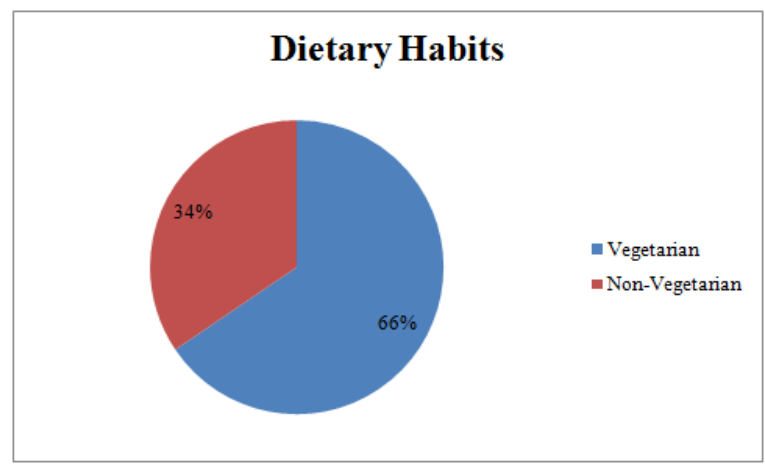

Figure 6. Study Population of Dietary Habits

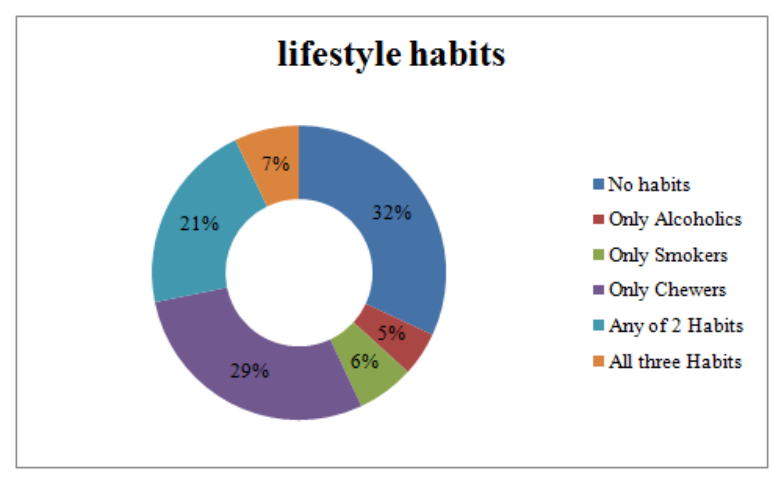

Figure 7. Study Population of Dietary Habits
Table 2: Comparison of semen parameters with respect to their lifestyle habits (Values are in Mean \pm S.E)

\begin{tabular}{|l|c|c|}
\hline Parameter & $\begin{array}{c}\text { Sperm Count } \\
\left(\begin{array}{c}\text { millions/ml }) \\
(\mathrm{n}=196)\end{array}\right.\end{array}$ & $\begin{array}{c}\text { Normal } \\
\text { morphology }(\%) \\
(\mathrm{n}=196)\end{array}$ \\
\hline Smokers $(\mathrm{n}=54)$ & $33.70 \pm 1.29$ & $14.65 \pm 0.32$ \\
\hline $\begin{array}{l}\text { Non-smokers } \\
(\mathrm{n}=142)\end{array}$ & $49.96 \pm 3.22$ & $16.23 \pm 0.24$ \\
\hline Chewers $(\mathrm{n}=168)$ & $36.60 \pm 1.88$ & $13.65 \pm 0.51$ \\
\hline $\begin{array}{l}\text { Non-chewers } \\
(\mathrm{n}=163)\end{array}$ & $39.84 \pm 2.40$ & $15.89 \pm 0.54$ \\
\hline Alcoholic $(\mathrm{n}=54)$ & $34.23 \pm 1.61$ & $15.61 \pm 0.40$ \\
\hline $\begin{array}{l}\text { Non-alcoholic } \\
(\mathrm{n}=167)\end{array}$ & $40.46 \pm 4.44$ & $16.47 \pm 1.02$ \\
\hline
\end{tabular}

\section{Conclusions}

The growing body of literature showing that wide variety of substances adversely affects the semen quality. In order to characterize risk assessment in better way it might be useful to revise the ways to report the damage to sperm quality and quantity the amount of toxic exposures on similar male endpoints. Progress in medicine can only be achieved if efforts are made for better understanding of the etiology of male infertility. Future development should proceed in the areas on blastocyst transfer, maximizing the implantation window, better sperm selection methods and the understanding the role of capacitation in ART successes. IMSI can be recognized as a promising technique that has fostered deeper understanding of the mechanisms interfering with male fertility potential in both natural and assisted reproduction. The present data suggest that lifestyle factors such as tobacco smoking or chewing and/or alcohol consumption have some role in deteriorating male reproduction. Therefore, awareness programmes should be conducted towards specific group who has having such habits. In addition, the person who has habit of tobacco chewing or smoking and/or alcohol consumption undergoing for infertility treatment should be advised about the adverse effect of such habits on male reproductive function.

\section{References}

1. Pasqualotto FF, Sobreiro BP, Hallak J, Pasqualotto EB, Lucon AM. Cigarette 
smoking is related to a decrease in semen volume in a population of fertile men. BJU Int 2006. Feb;97(2):324-326

2. Vine MF. Smoking and male reproduction: a review. Int J Androl. 1996 Dec;19(6):32337.

3. Vine $\mathrm{MF}$, Tse $\mathrm{CK}, \mathrm{Hu} \mathrm{P}$, Truong KY. Cigarette smoking and semen quality. Fertil Steril 1996. Apr;65(4):835842

4. Zhang JP, Meng QY, Wang Q, Zhang LJ, Mao YL, Sun ZX. Effect of smoking on semen quality of infertile men in Shandong, China. Asian J Androl 2000. Jun;2(2):143146

5. Wang SL, Wang XR, Chia SE, Shen HM, Song L, Xing HX, et al. A study on occupational exposure to petrochemicals and smoking on seminal quality. J Androl 2001. Jan-Feb;22(1):73-78

6. Künzle R, Mueller MD, Hänggi W, Birkhäuser $\mathrm{MH}$, Drescher $\mathrm{H}$, Bersinger NA. Semen quality of male smokers and nonsmokers in infertile couples. Fertil Steril 2003. Feb;79(2):287-291

7. Storgaard L, Bonde JP, Ernst E, Spano M, Andersen CY, et al. Does smoking during pregnancy affect sons' sperm counts? Epidemiology. 2003; 14:278-86.

8. Jensen TK, Jorgensen N, Punab M, Haugen TB, Suominen J, et al. Association of in utero exposure to maternal smoking with reduced semen quality and testis size in adulthood: a cross-sectional study of 1,770 young men from the general population in five European countries. Am J Epidemiol. 2004; 159: 49-58.

9. Said TM, Ranga G, Agarwal A. Relationship between semen quality and tobacco chewing in men undergoing infertility evaluation. Fertil Steril 2005; 84: 649-53.

10. Shi, Q., Ko, E., Barclay, L., Hoang, T., Rademaker, A., \& Martin, R. (2001). Cigarette smoking and aneuploidy in human sperm. Molecular Reproduction and Development, 59(4), 417-421.

11. Robbins WA, Elashoff DA, Xun L, Jia J, $\mathrm{LiN}, \mathrm{Wu} \mathrm{G}$, et al. Effect of lifestyle exposures on sperm aneuploidy. Cytogenet Genome Res 2005; 111(3-4):371-7.

12. Ramlau-Hansen $\mathrm{CH}$, Thulstrup AM, Storgaard L, Toft G, Olsen J, et al. (2007) Is prenatal exposure to tobacco smoking a cause of poor semen quality? A follow-up study. Am J Epidemiol 165: 1372- 1379.

13. Sorahan T, Lancashire R, Prior $P$ et al. Childhood cancer and parental use of alcohol and tobacco. Ann Epidemiol 1995; 5: 354-9. 78.

14. T. W. Boyden and R. W. Pamenter (1983) Effects of ethanol on the male hypothalamic-pituitary-gonadal axis. Endo. Rev. 4, 389-395.

15. Pajarinen J, Karhunen PJ, Savolainen V, Lalu K, Penttilä A, Laippala P. Moderate alcohol consumption and disorders of human spermatogenesis. Alcohol Clin Exp Res 1996; 20:332-7.

16. Tielemans E, Burdorf A, te Velde ER et al. Occupationally related exposures and reduced semen quality: A case control study. Fertility and Sterility. 1999; 71:

17. Muthusami KR, Chinnaswamy P. Effect of chronic alcoholism on male fertility hormones and semen quality. Fertil Steril 2005;84(4):919-24.

18. TsujimuraA(1), Matsumiya $\mathrm{K}$, Takahashi $\mathrm{T}$, Yamanaka M, Koga M, Miura H, effect of lifestyle factors on infertility in men. Arch Androl. 2004 Jan-Feb; 50(1):15-7.

19. Donnelly GP, McClure N, Kennedy MS, Lewis SEM. Direct effect of alcohol on the motility and morphology of human spermatozoa. Andrologia. 1999; 31:43-47.

20. Magnusdottir EV, Thorsteinsson T, Thorsteinsdottir S, Heimisdottir M, Olafsdottir K. Persistent organochlorines, sedentary occupation, obesity and human 
male subfertility. Hum Reprod. 2005 Jan; 20(1):208-15.

21. Nguyen RH, Wilcox AJ, Skjaerven R, Baird DD: Men's body mass index and infertility, Hum Reprod 22(9):2488-2493, 2007

22. Sallmen M, Sandler DP, Hoppin JA, Blair A, Baird DD. Reduced fertility among overweight and obese men. Epidemiology. 2006; 17(5):520-523.

23. Jensen TK, Andersson AM, Jorgensen N, Andersen AG, Carlsen E, Petersen JH, et al. Body mass index in relation to semen quality and reproductive hormones among 1,558 Danish men. Fertil Steril. 2004 Oct; 82(4):863-70.

24. Koloszár, S., Fejes, I., Závaczki, Z., Daru, J., Szöllosi, J., \& Pál, A. (2005). Effect of body weight on sperm concentration in normozoospermic males. Arch Androl. 2005 Jul-Aug; 51(4):299-304.

25. Fejes, I., Koloszár, S., Závaczki, Z., Daru, J., Szöllösi, J., \& Pál, A. (2006). Effect of body weight on testosterone/estradiol ratio in oligozoospermic patients. Arch Androl. 2006 Mar-Apr; 52(2):97-102.

26. Kort HI, Massey JB, Elsner CW, MitchellLeef D, Shapiro DB, Witt MA, Roudebush WE. Impact of body mass index values on sperm quantity and quality. J Androl. 2006 May-Jun; 27(3):450-2. Epub 2005 Dec 8.

27. Aggerholm AS, Thulstrup AM, Toft G, et al. Is overweight a risk factor for reduced semen qualityand altered serum sex hormone profile? Fertile Steril. 2007; In press

28. Hammond AO, Gibson M, Peterson CM et al. Obesity and alteration in sperm parameters. Fertil Steril. 2008; ; In press

29. Bracken MB, Eskenazi B, Sachse K, McSharry JE, Hellenbrand K, Leo-Summers L. Association of cocaine use with sperm concentration, motility and morphology. Fertil Steril. 1990 Feb; 53(2):315-22.

30. Thonneau $\mathrm{P}(1)$, Bujan L, Multigner L, Mieusset R. Occupational heat exposure and male fertility: a review. Hum Reprod. 1998 Aug; 13(8):2122-5.

31. HjollundNH, Bonde JP, Jensen TK, Olsen J. Diurnal.Impact of diurnal scrotal temperature on semen quality. Reprod Toxicol 2002; 16:215-21. 67

32. Hjollund $\mathrm{NH}(1)$, Storgaard L, Ernst E, Bonde JP. The relation between daily activities and scrotal temperature. Reprod Toxicol. 2002 May-Jun; 16(3):209-14.

33. Jung A(1), Schuppe HC. Influence of genital heat stress on semen quality in humans. Andrologia. 2007 Dec; 39(6):203-15.

34. Figà-Talamanca I(1), Cini C, Varricchio GC, Dondero F, Gandini L, Lenzi A. Effects of prolonged autovehicle driving on male reproduction function: a study among taxi drivers. Hum Am J Ind Med 1996;30:750-8

35. Jung A, Leonhardt F, Schill WB, Schuppe HC.Influence of the type of undertrousers and physical activity on scrotal temperature. Hum Reprod. 2005 Apr;20(4):1022-7

36. Eskiocak S(1), Gozen AS, Yapar SB, Tavas F, Kilic AS, Eskiocak M. Glutathione and free sulphydryl content of seminal plasma in healthy medical students during and after exam stress.Hum Reprod. 2005 Sep; 20(9):2595-600.

37. Clarke RN (1), Klock SC, Geoghegan A, Travassos DE. Relationship between psychological stress and semen quality among in-vitro fertilization patients.Hum Reprod. 1999 Mar; 14(3):753-8.

38. Ragini G, Caccamo A. Negative effect of stressof in vitro fertilization program on quality of semen. Acta Eur Fertil 1992;23:21-3

39. Fejes I, Zavaczki Z, Szollosi J, Koloszar S, Daru J, Kovacs L, Pal A. Is there a relationship between cell phone use and semen quality? Arch Androl 2005;51:385-93

40. Wdowiak A, Wdowiak L, Wiktor H.Evaluation of the effect of using mobile phones on male fertility.Ann Agric Environ Med. 2007;14(1):169-72. 
41. Agarwal et al., "Effect of Cell Phone Usage on Semen Analysis in Men Attending Infertility Clinic: An Observational Study," Fertility and Sterility 89, 124 (2008).

42. Swan SH. semen quality in fertile US men in relation to geographical area and pesticide exposure. Int J Androl. 2006 Feb;29(1):62-8

43. Carreño, J., Rivas, A., Granada, A., and Lopez-Espinosa, M. J. 2007. Exposure of young men to organochlorine pesticides in Southern Spain.Environ Res. 2007 Jan;103(1):55-61.

44. Robins TG, Bornman MS, Ehrlich R er al. Semen quality and fertility of men employed in a South African lead acid battery plant. Am J Ind Med 1997; 32:36976

45. Irgens A, Kruger K, Ulstein M. The effect of male occupational exposure in infertile couples in Norway. J Occup Environ Med 1999;41(12):1116-20.

46. Benoff S, Jacob A, Hurley IR. Male infertility and environmental exposure to lead and cadmium. Hum Reprod Update 2000;61107-21.

47. Sram R, ed. Teplice Program: Impact of Air Pollution on Human Health. Prague, Czech Republic: Academia, 2001, pp. 167-180.

48. Paolo Mocarelli, Pier Mario Gerthoux.Dioxin Exposure, from Infancy through Puberty, Produces Endocrine Disruption and Affects Human Semen Quality.Environ Health Perspect. 2008 Jan; 116(1): 70-77.

49. Bigelow PL, Jarrell J, Young MR, Keefe TJ, Love EJ. Association of semen quality and occupational factors: comparison of casecontrol analysis and analysis ofcontinuous variables.Fertility and Sterility.1998;69:118.

50. Jensen TK, Bonde JP, Joffe M. The influence of occupational exposure on male reproductive function.Occupational Medicine. 2006; 56:516-20.
51. Cherry N, Moore H, McNamee R, et al. Occupation and male infertility: glycol ethers and other exposures. Occup Environ Med 2008; 65:708-714.

52. J Mendiola1, AM Torres-Cantero , JM Moreno-Grau, J Ten, M Roca, S MorenoGrau , R Bernabeu.Exposure to environmental toxins in males seeking infertility treatment: acase-controlled study. Reproductive BioMedicine Online 2008.

53. Bonde JP. The risk of male subfecundity attributable to welding of metals. Studies of semen quality, infertility, fertility, adverse pregnancy outcome and childhood malignancy.Int J Androl. 1993 Aug;16 Suppl 1:1-29.

54. Chia SE, Tay SK.Occupational risk for male infertility: a case-control study of 218 infertile and 227 fertile men.J Occup Environ Med. 2001 Nov;43(11):946-51.

55. Cherry N, Labrèche F, Collins J, Tulandi T. Occupational exposure to solvents and male infertility. Occup Environ Med. 2001;58:635-640.

56. Xiao G(1), Pan C, Cai Y, Lin H, Fu Z.Effect of benzene, toluene, xylene on the semen quality of exposed workers.Chin Med J (Engl). 1999 Aug;112(8):709-12.

57. De Rosa M, Zarrilli S, Paesano L, Carbone U, Boggia B, Petretta Metal (2003) Traffic pollutants affect fertility in men.Reprod Biomed Online 16(2):218-226

58. Varghese AC, Agarwal A. The genetic causes of male factor infertility: a review.Fertil Steril. 2010 Jan;93(1):1-12.

59. Van Waart J., Kruger T.F., Lombard C.J., and Ombelet W. 2001. Predictive value of normal sperm morphology in intrauterine insemination (IUI): a structured literature review. Hum Reprod 7; 495-500.

60. Kruger, T.F., Menkveld, R., Stander, F.S.H. et al."Sperm morphologic features as a prognostic factor in in-vitro fertilization. International journal of Fertility and Sterility". Vol 46, pp 1118-1123.1986 
61. Kruger, T.F., Acosta, A.A., Simmons, K.F. et al. Predictive value of abnormal sperm morphology in in-vitro fertilization International journal of Fertility and Sterility. Vol 49,pp 112-117.1988

62. Coetzee, K., Kruger, T.F. and Lombard, C.J. "Predictive value of normal sperm morphology: a structured literature review. Asian journal of Human Reproduction. Update", Vol 4, pp 73-82.1988

63. Kruger TF, Van der Merwe J, Van Waart J: The Tygerberg Strict Criteria: What Are the Clinical Thresholds for in vitro Fertilization? Intrauterine Insemination and in vivo Fertilization? In: Kruger TF, Franken DR (eds.). Atlas of Human Sperm Morphology Evaluation. London, Taylor \& Francis, 2004:13-18.

64. World Health Organization. Manual for the examination of sperm and sperm-cervical mucus interaction. 4th Edition. Cambridge University Press 2003.

65. World Health Organization. Manual for the examination of sperm and sperm-cervical mucous interaction. 3rd Edition. Cambridge University Press. 1992.

66. http://www.progres-camera.de 